\title{
Post Merger-Acquisition Integration (Theoretical Approach and Applied) for Jordan Companies
}

\author{
Dr. Mohammad. M. Alalaya \\ Associate Prof. \\ Economics and Quantitative Methods \\ Dr. Jihad . Alfarajat \\ Department of Business Management \\ Al-Hussein Bin Talal University \\ College of Administrative Management and Economics \\ Jordan
}

\begin{abstract}
This study as other previous studies find that theory puts has a higher consequence as outcome arising from preexisting structural characteristic. Also there is clear evidence that complexity is the most predominate, enhance, this study aims to examine the performance of merger-acquisition of organization as it involves the preestablished structural specific characteristic, as team behavior, infrastructure support, organization complexity, enhance the effect task structure, and motivation, also the willingness to share information and cultural unification. The extent to which the organizational provides infrastructure of firms support is also quite in adequate levels, and expected to have a positive correlation with the post merger outcomes for the Jordanian companies. Individuals- willingness to have the information is in the lowest level of association with the performance and integration of the organization. Counterintutively, the analyzed leading to a cohesive of behavioral theory of the post merger, and has a paves away of the scholar to study and applied the integration dynamics and using mathematical models which can be tailored as a specific circumstances.
\end{abstract}

Keywords: post merger-acquisition, integration, organizational performance,

\section{Section one}

\section{Introduction}

\section{1 -1: Problem Statement}

The merger and acquisition (M \& A) was become in the last decade an important thinks to achieve significant resource commitments, also to dictate the fortunes of companies in order to involve for future periods. The researchers focus on less tangible social factors such as psychological factors related to integration of merger and acquisition firms, more than traditional financial and strategic perspectives. Due to the importance merger and acquisitions which considered an important factor of business growth and its relevance to family firms, and the interplay between these aspects influences what people perceive as organizational culture in terms of theories, concepts and research in the field of organizational behavior and to engage in reflective dialogue the analytical skins of Jordanian companies of the theoretical frame works, challenges and dilemmas facing the field. Norms and value in a specific setting.

\section{2 - 1: Objective goals of the study}

This study aims to offer as other past papers of researcher's introduction core

Theories, concepts and research in this field of organization behavior, also to engage in reflective dialogue the analytical skills of Jordanian of the theoretical frameworks, challenges and dilemmas facing this field. This study also aims to show the value creation during the post merger-acquisition integration of companies if there is integration of any degree ,enhance also to have an idea of the success factors which can evaluate the integration speed on efficiency of applied the merger -acquisition in the Jordanian companies. 


\section{3 -1: Previous Studies}

(Teerikanas, 2006) in his study defines the integration as a process which can Leads the process to success with integrating of some factors cooperate together to create the product such as administrative, organizational structure, financial system, communication system, operative system ( $\mathrm{R} \& \mathrm{D}$, marketing, production system) these factors as a multidirectional factors cooperate in their effect together with mergers should make it more facile for all company departments to make their functions harmoniously with the combined entity where (Pitkethly, et al, 2003) studied the integration with less important of how business of adequate integration, can join the operation, also they have ranked the integration from low to high level, passing through the adequate levels, enhance the stated that is herded it is to execute integration in their study they focusing on two categories by differentiating the holding categories, where the acquiring company is attempting a turn round but with out of any degree of integration. While symbiosis assumes a certain degree of changes in both companies. Mergers acquisitions (M \& As) have drawn attention and an important subject for researcher, and manifold view point also taken a large space of thinking of many researchers, these taken a numerous factors apparently influencing the success of $\mathrm{M} \& \mathrm{~A}$ projects and these leads to extremely fragmented body of knowledge with although logical strive for integration has been expressed by these researchers.

A numerous factors which manifold criteria for evaluation have been identified by the researchers. The theories and polices of how these factors interact in culmination with each other to curette the success of the project or a company. Some authors focus in success of family business such as (Astrac-+han, 2010) in his paper, he is care at the factors aspects the growth and success of these family firms. The 2008). socio culture pattern has a place of originating from family influence on business (Hall, et. (Holladner and Elman, 1988) have pointed to the risk of over simplification in focusing to the founder in the process of cultural development these founders influences is filtered through the behavior of management team in the firm or company many researcher has introduced the concepts owner-conterie cultures to whole family rather than solely. The largely offset by situation which occur during the post - merger integration of companies making a value gap, which refers to different between the expected value of the post-merger company which can be measured by some independent value of each company value gap happen between two merger companies which includes:

- Experience of company.

- Management wars.

- Failure to change and to manage risk.

- Integration.

- Loss of vision and leak of this vision.

- Poor communication with others.

- Culture clashes.

The extent to which the organize can provides infrastructure support to the firms is supporting the common exception that organizational complexity is a powerful influential characteristic on integration and performance. Through in organic extension, this approach is typically involves a merger with, or an acquisition of (Capron and Mitehell, 2012) stated that a merger- or acquisition has a high degree of execution - risk inherent in it is boundless complicity. This study concentrate of two prominent concerns with two classified characteristics that can be considered as a) cultural and b) as structural, enhance, with regard to post - merger out comes from the success process the concern of many papers also this study is: a) the organizations performance and b) the degree of cultural unification in regard to the antecedent features of integration.

Focusing managerially on direct - controlled features such as: a) the structure of works and team works, b) the level of infrastructure supported provided by the organization, c) organization and team level complexity, d) the behavioral characteristic such as individual predisposition for seeking an information, and focusing on the assigned task this can be considered as preexisting characteristics of integral facts of an organization learning system, which a compounded with the mat-ovation of team works in a firms and as a result of organization's learning process ultimately affect the performance of the dynamic organization this can be achieved by the dynamics of knowledge (information) diffusion within the combined organization.

(Calpin, 2010) offers the delitorat that management follows during the post-merger integration period is primary to the determination of integration success or failure. Where (Epstein, 2004) suggested several drivers of merger success that includes sociality-slated factors such as coherent integration strategy. 
We can classify the researcher of merger and acquisition in to three groups or categories; organizational and process-oriented strategies, and financial (Marks and Mirvis, 2001). Studied the potential problems in managing changes during the integration as (Franlkner and cambell, 2003), the team of administrative in a company may also contribute to achieving cost reductions, if the previous team was profligate.

It is a process of adaption, this adaption can be occur through company perform, and transfer of completeness to achieve acquisition goals with the team of worker is the company the post integration of merger and acquisition of companies take a large space of authors some of them considered it as a motor of the organizational change and development, and put in their account it is overall regeneration strategy which can be includes the red employee and the disposal of intangible and tangible resources of companies, also the reconfiguration of these companies as (Chakrabarti and Mitehell, 2004; Elsass and Veiga, 2006) and (Nemanich and Vera, 2009).

\section{Section two:}

\section{Literature Review:}

$1-2$ : The fine success drivers of post-acquisition integration which leads to profitability and to forward gains in companies are:

- Planning strategy, serious integration team, coherent integration finally communications, but we can add two possible drivers that ability and personality of leader to guard for ward then commandment of post-merger acquisition.

- The leading team of worker and managing the process in the companies and change the previous policy and change leading to increase profitability, (Harbison et. al, 1999) draw and determined the three elements which are necessary for change.

Table (1): Element of Changes

\begin{tabular}{|l||l||l||l||}
\hline Vision & Architecture & Leader Ship & Out Come \\
\hline \hline Available & Available & Available & Successful post-acquisition integration \\
\hline \hline Available & Available & Available & Change isn't cascaded throughout both compar. \\
\hline \hline Not available & Available & Available & Lacks direction of new interspersion \\
\hline \hline Available & Not available & Available & No process of integration \\
\hline \hline Not available & Available & Available & Bureaucrat \\
\hline \hline Not available & Not available & Not available & An academic exercise \\
\hline \hline Available & Available & Available & Empty char \\
\hline
\end{tabular}

Source : Harbison et al ,1988,pp.8

Authors in this field studied the factors of integration such as: defining and managing deadlines, budgeting integration costs, the forming and implementing of communication strategies, synergy monitoring, involving different key people during integration cultural issue, therefore -seur or determinate different factors affecting (Epstein, 2004) summarized the importance of integration speed, and the five drivers of success in corporate integration: 
Table(2): drivers of success in corporate integration.

\begin{tabular}{|c|c|c|c|}
\hline & Merger & Acquisition & Conglomerate \\
\hline $\begin{array}{l}\text { Integration } \\
\text { Strategy }\end{array}$ & $\begin{array}{l}\text { Promote "merger of equals". } \\
\text { Meritocratic decisions. } \\
\text { Practices chosen without respect to } \\
\text { previous companies' practices. }\end{array}$ & $\begin{array}{l}\text { Create impression that acquired com- } \\
\text { pany was "always there". Acquired } \\
\text { company adopts practices of acquir- } \\
\text { ing company. }\end{array}$ & $\begin{array}{l}\text { No major changes in new company. } \\
\text { Assimilation of new company in cer- } \\
\text { tain key areas, and some oversight } \\
\text { functions added. }\end{array}$ \\
\hline $\begin{array}{l}\text { Integration } \\
\text { Team }\end{array}$ & $\begin{array}{l}\text { Full-time, discrete team with ample } \\
\text { resources and contributions from } \\
\text { senior management. } \\
\text { Equal contributions from both com- } \\
\text { panies. }\end{array}$ & $\begin{array}{l}\text { Small, discrete team with ample } \\
\text { resources and contributions from } \\
\text { senior management. } \\
\text { Leadership from acquired company } \\
\text { remains. }\end{array}$ & $\begin{array}{l}\text { Leadership from acquired company } \\
\text { remains. } \\
\text { Management participation in both } \\
\text { companies to promote knowledge. }\end{array}$ \\
\hline $\begin{array}{l}\text { Communica- } \\
\text { tion }\end{array}$ & $\begin{array}{l}\text { Customers of both companies must } \\
\text { understand changes in business. } \\
\text { Employees of both companies must } \\
\text { understand new roles and opportuni- } \\
\text { ties. } \\
\text { Focus on how companies fit together. }\end{array}$ & $\begin{array}{l}\text { Customers of acquired company must } \\
\text { understand new opportunities in } \\
\text { business. } \\
\text { Employees of acquired company } \\
\text { must understand new roles. } \\
\text { Focus on how acquired company fits } \\
\text { into acquiring company's business. }\end{array}$ & $\begin{array}{l}\text { Few changes for customers. } \\
\text { Parent company must understand } \\
\text { how new company operates and } \\
\text { any new synergies. } \\
\text { New company must understand } \\
\text { parent company's practices and } \\
\text { opportunities }\end{array}$ \\
\hline Speed & $\begin{array}{l}\text { Fast decisions are key for both strate } \\
\text { gic goals and promoting stability and } \\
\text { reducing uncertainty in organization. }\end{array}$ & $\begin{array}{l}\text { Fast decisions are key for both strate- } \\
\text { gic goals and promoting stability and } \\
\text { reducing uncertainty in organization. }\end{array}$ & $\begin{array}{l}\text { Fast decisions are primarily impor- } \\
\text { tant for reducing uncertainty in } \\
\text { organization }\end{array}$ \\
\hline $\begin{array}{l}\text { Aligned Mez- } \\
\text { sures }\end{array}$ & $\begin{array}{l}\text { Balance between financial and non- } \\
\text { financial measures. } \\
\text { Tracking of revenue and const syner- } \\
\text { gies }\end{array}$ & $\begin{array}{l}\text { Focus on how acquired company } \\
\text { builds company growth and reduces } \\
\text { costs. } \\
\text { Acquired company adopts measure- } \\
\text { ment systems of acquiring company. }\end{array}$ & $\begin{array}{l}\text { Most internal measurement stays } \\
\text { same for new company. } \\
\text { New measures added to assimilate } \\
\text { new company into parent com- } \\
\text { pany. }\end{array}$ \\
\hline
\end{tabular}

Source: Epstein, 2004, 180

Many researchers who emphasize that it is not enough to perform adequate activities for achieving acquisition goals, and integration are not quickly realized, also they have emphasize that slower pace can interfere with innovations and prevent companies from achieving synergies' (Homburg \& Bucerias, 2006; Colombo, et. al, 2007; Epstien, 2004) and wyman et, al, 2008). Who are in their studies provide certain data that integration speed can have a positive impact on the success of merger and acquisition but usually stressed that fast implementation of change speed is useful for companies some of the says that it reduced the cost, others added that it can be minimize the scope of uncertainties.

We can support the table (2) by a diagram of impact integration speed on a companies on performance improvement the results which we can conclude that we can detailed of integration phase, sources of value in companies applied the post-merger acquisition integration can faced the challenges of transform of knowledge and management skills, else cultural of organization due to the value distraction and employee resistance and the in compatibility of new culture, but other over coming issues and factors, which can create barriers to achieving the goals of comprise and success with the adequate management. 
Figure (1):

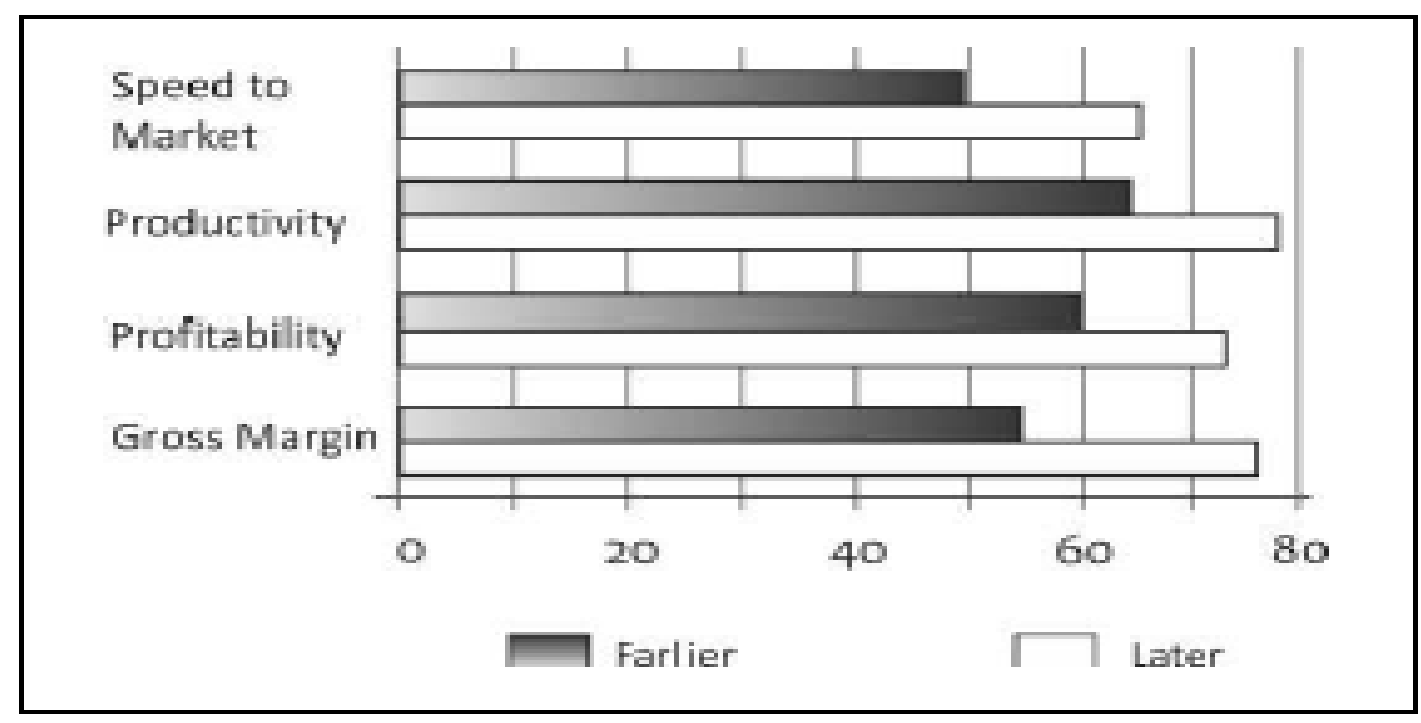

Our study mainly endeavors to enable mergers to provide such responds to the drivers and factors which affecting success through the dynamic merger-acquisition integration. We can say that our study can formulate a port of a comprehensive of a behavioral theory through economic measurements and not covers all parts of theory. The main motive of the merger was to achieve cost synergies in production, sales marketing. When a problems in the organization arise in the integration, the post-merger integration ,must be have a design to be success or fail, but nevertheless going back because he deal sours it can be abandoned, though there can be significant financial and reputational loss.

\section{2-2 : Definition of post-merger acquisition integration of companies:}

This process beginning at the moment of the sighing of agreement, also it is usually seen as a long - term and open process. This process involves whole activities which should make the progress and secure the efficient of management of organizational activities which can achieve a set of organizational activities and goals. The postmerger-acquisition can be seen as, the integration and combining a series of management initiatives and related to issues of the companies an evolving a series of management initiatives and planned activities, also it is viewed as determining the level of integration, which can be considered as autonomy delegated to the acquired company. The hybrid organization is formed; in this process as the adequate management can create the value creation due to the mutual depends of interdependence. (Teerikangas, 2006) define the post-merger-acquisition integration as:

1- Process dealing and care of compensation and communication system, financial system, operative systems (production, markefing, $\mathrm{R} \& \mathrm{D}$ ) and as result of whole process, dealing with administrative organizational structure. Post-acquisition can be executed an many level.

2- Depends on the circumstances around the companies as external environment and external environment, one of them the physical level which interest of production lines and technology.

The socio, Culture of organizational integration which included many factors such as; the development of culture of organizational for companies, changes of organizational culture to new culture, the selection type of management and how the adaptation with new entity. (Pilkethly, et al, 2003), not give great interest to the speed of integration between companies, but focused not how it happen, but if it executed on adequate level, they ranked the level of integration from low to high, the acquired company can integrated partially with other company, company can merger into organizational figure of integration. Many authors as (Nahava ndi and Melekkzadeh, 1988) and (Kimberly and Lanint, 2004) they have studied the harmonization culture of post merger-acquisition as a different degrees of relatedness between the two companies and a degree of tolerance of different culture surrounded the companies. In general the integration process required a degree of change in both companies to create the competences and to adapt the leading practices in order to combined them together, therefore the stages can be performed as transferring strategy completeness, and have initial protection which can followed by a period a gradual involvement (merging and combining) to establishing a balance between companies goals, administrative system and resistance of employment. 


\section{3 -2 : Cultural a Spects of Post-merger-acquisition:}

Integration between companies with similar business activities, has become from 1990s as merger wave up to now and most concerned in management, and it is become one of the most important factors of success which has been the ability to manage firm and important to integrate the merging organizations. (Vaara, 2005), emphases that move from the prevailing culture perspective, being the dominate paradigm in studies of $\mathrm{M} \& \mathrm{~A}$ integration towards new aspects. The firms who works on an international erena may need to kow more about mergeracquisition since most of direct investmants is by merger-acquisition (Steen \& Welch, 2006). Some authors such as (Ben - Amar \& Andre, 2006) stated that throug the family owership and the impact on value creation, the firm of business family can managed a harm any with the local culture and can have a higher level of long-run productivity, but if they have understand well the cultural assumptions of the social community (Astrachan, 1988) (Miller et al, 2010), reported inn their paper that there is more attention and need to distinguish between business risk and portfolio risk as their implications catiors for family firms acquisition. The priority on socio-emothional wealth suggests that family firms are less likely to acquir other firms (Gomes et al, 2010). (Kund, 1992) stated that beside formal control, normative control through organizational culture in family business setting it includes the family and it is ifluence on the culture process. Where (Sorenson, 2000) includes leadership styles that influence the family business outcomes as well as employee satisfaction and commandment. This can gove appositive results outcomes as sorenson this can be cleard in larger organization which can interplay between merger and owners on their influence of their culture. Many of the researcher stated that the separation of ownership and management is crucial to understand the influence during the integration process in culture influence measurement many scales has been developed as F-Pec scale of family influence and used these dimensions into a contingency model of family business board. (BSC) balanced socre card by (Craig and Moores, 2005), (FCs) family climate scales, which developed by (Biornberg and Nicholson, 2007), many scales alo has been developed to measure the organizational complexities.

\section{4-2 : The variables of study:}

Many variables can be effected the post-merger integration such as:

1- The actor specialization: the value lied between I to zero, this can be assigned to the actor which are entirely unique to all other actors in the same team the tast nods has only one tie to the actor node in the task-agent matrix.

2- Team interdependence:

The value 1.00 indecates that non-actor-specialization task is a signed to the all actors in the work-team with implying a highly collaborative task.

3- Willingness to seek: it is a fraction of the team periods that an actor will be active in the inter action search proccess the willingness to seek value can be between 0.00 and 1.00 .

4- Willingness to share: this variable takeson a value 0.0 and of the knowledge. Where comperision to the extreme at 1.00 the actors consider to share their known knowledge's when interacting with a partner the rananom selection is made to determine the specific concept to be shared.

5- Percentage of task knowledge: it calculated by the number of ties in the actor knowledge network it can be calculated by divided the number of unique actor knowledge required to task network times actor knowledge.

6- Exehange-motivation outreach: it indecates to the numbers of enthusiasm for sharing information with others as to make the unique information accessible to others. Also this information transfer enables culture intergration with and task performance to other group.

7- Cultural complexity: is of immediate relevance in the post-merger intergration proccess due to the unify two culture into a single culture in new company members of Alpha will be exposed to be specific culture traits of beta and visa-versa, the complexity will lead to more complex integration this process performance, and the organizational culture concepts are transferred in its place.

The culture complexity can be regarded as richness of exoticness of culture itself and conceived as number of attributes unique to a given culture.

\section{Section three:}

\section{Data and methodology:}

The data related to the post-merger-acquisition depends on accurate response wich essentially impossible to collect, due to that any organization, and even just general access to the organization. 


\section{Section for:}

\section{Hypothsis of study and empirical results :}

This study was conducted to the simulation model and to answer the three hypotheses:

$\mathbf{H}_{\mathbf{1}}$ : what are the differences between organizations, on fulfilled task-knowledge transfer level.

$\mathbf{H}_{2}$ : the hypothesis is formally stated depends to the variables of the study such as the degree to which study such as the degree to which employees specialize, level of term interdependence, willingness to seek thus the hypothesis stated as:

a. What are the quantifiable effects of the differences between two merger-integrated companies on taskknowledge transfer with respect to antecedent?

b. What are the quantifiable effects of two companies' difference on task-knowledge with respect to the antecedent, relative to the task- assignment structure?

H3: what is the effect of pre-established cultural complexity on the diffusion of culture and task management and the effect of cultural exchange motivation.

When we applied the study of two post-merger companies integration we focused on each hypothesis as below:

On first hypothesis we established the following points:

a. The team level complexity has a dynamic characteristically similar to that of organization level complexity.

b. The organization with lower level of complexity will make noticeable progress in task knowledge diffusion.

c. The infrastructure support positively affects the task knowledge transfer rats.

d. The difference between team level complexity has minimal effect on the task knowledge transfer.

In the second hypothesis we have concentrate on the following points:

a. The organization with lots of interdependence work-team many require less attention during the post-merger integration.

b. The effective proccess to focus on information exchange only to a point of critical mass rather than to attend to all members of organization.

Hypothesis three imposes the following points:

a. The mergers may safely not be overly concerned about motivating the numbers of the acquired organization to share information.

b. During the pest-merger integration made required less attention of in connected work group. Empirical results

Table ( )

\begin{tabular}{|l||l|}
\hline The control variables & Values \\
\hline \hline Organization team-work complexity & \\
\hline \hline Actor per team first company & $3,7,12$ \\
\hline \hline Actor per team second company & $0,9,5,0$ \\
\hline $\begin{array}{l}\text { Infrastructure support knowledge per team ration second } \\
\text { company }\end{array}$ & $0,7,3,0,5$ \\
\hline $\begin{array}{l}\text { Organization complexity team per organization (both } \\
\text { companies) }\end{array}$ & $3,8,2,0$ \\
\hline \hline
\end{tabular}

All results are greater zero or equal to zero in this table the results of main three control variables and subdivide as line control variables and one response variable the task knowledge fine transferee level, the control variables include:

a. The number of actor (agents) per team work for both companies, while makes up the complexity.

b. Number of organization specific knowledge concepts per team of two integration companies which make up infrastructure support.

In table ( ) we have applied the OLs of the relationship between control variables and task knowledge transfer. The result of Ols regression indicates that $\left(\mathrm{R}^{2}=0.816\right)$ of the variance of task - knowledge transfer other results in table ( ) below. 
Table ( ): Ols regression estimation for relationship between control variables and task - knowledge transfer.

\begin{tabular}{||l|l||l||}
\hline Variables & Cofficient estimate & Prob value \\
\hline Intercept (time) & $0.5632^{* *}$ & $(0.00023)$ \\
& $0.000179^{* *}$ & $(0.000)$ \\
\hline \hline Organization complexity team per org. & $-0.00875^{* * *}$ & $(0.00001)$ \\
\hline Team complexity Agents / team of company 1 & $-0.0006634^{* *}$ & $(0.0004)$ \\
\hline Team complexity Agents / team of company 2 & $-0.00319^{* *}$ & $(0.00035)$ \\
\hline Infrastructure support & -0.00411 & $(0.00002)$ \\
\hline Knowledge concepts per team (I) & & \\
\hline Knowledge concepts per team $(2)$ & -0.0385 & $(0.000)$ \\
\hline $\mathbf{R}^{2}=\mathbf{0 . 8 1 6}$ & & \\
\hline
\end{tabular}

All second company coefficients statistically significant and each control variable has a negative effect of taskknowledge transfer. As the results of organization complexity in both integration companies increase the expected task - knowledge transfer level will decrease. The infrastructure support has a positive, also the number of knowledge concepts has a negative sign therefore we can say that the same or monotonically increase over time a cording to the model which use in this study. The outcomes variables specific to experiment in this study, where a single control variable is altered. First the rate of task-knowledge transfer is greater in the lower organization complexity over time. The team complexity for first company it appears that there is little statistical effect from varying the level of team complexity. Also, there is little statistical effect from varying the level of team complexity for $2^{\text {nd }}$ company. The results of infrastructure supports suggest that the variable is relevant and shows lower rate of change, and the same effect to the infrastructure support of and company therefore the OLs model can be formulated as below:

T ask - knowledge $=0.5632+0.000179$ time- 0.00875 Teamcomplexity- 0.0006634 Aqent perteamI - 0.00319 Agent peteam1 - 0.00411

\section{knoweldge concept sperteam1 - 0.0385knowledge conceptperteam}

The value of task-knowledge concepts in both integration competes is a contentious value between (0.00) and (1.00). The equation is consistent and confirm the explanatory visual analysis. These results emphasis the first hypothesis. Those deems to have eventual benefit relative to non-merger are quiet scarce to achieve any level of post-merger integration success eldudes most attempt (Harrison, 2007). It is common that an (M \& A) adeal is struck for the purpose of adding highly valued human resources the study snayed by recognizing the immense consequence of these human resource and the relevance of the informational aspects of their activities (Lin, 2006). To prove the second hypothesis two experiments are conducted within the realn of a computational model the computational model the construct based on agent-based simulation software developed and maintained by (carely - Martin \& Hirshman, 2009) also depends on representation model which based on the not work paradigm and follows dynamic network analysis, which imposes by (DNA: Carley, 2003) and (Ellioz \& Kiel, 2004); the consistent with agent based simulation model, also the social interaction by (Carely, 1986) to exchange knowledge with one another. The construct are discribed from an operational perspective which disrobed as control variables in this construct.

Table ( ): descriptive statistics for response variable $\mathrm{N}=7.213$ each experiment

\begin{tabular}{|l||l||l||l||l||}
\hline & Mean & Medium & Min & Max \\
\hline \hline Experiment. motivation & 0.63 & 0.61 & 0.48 & 0.95 \\
\hline \hline Experiment: structure & 0.76 & 0.72 & 0.57 & 0.83 \\
\hline \hline
\end{tabular}

Regards to motivation, we focused on two essential facts of information exchange aludividual to seek information, and willingness to share information also with regard to structure the study focused on a- the level of taskspecialization of the individuals. b- the team-level interdependence of individual necessary to perform their task the Ols regression as quantitative results. 
Table ( ): OLs regression result for structure and motivation effects.

\begin{tabular}{|c|c|c|c|}
\hline & & $\begin{array}{l}\text { Intercept \& lefficient- } \\
\text { estim }\end{array}$ & $\begin{array}{l}\text { Standardize } \\
\text { intercept/ coefficient }\end{array}$ \\
\hline 1. & Structure: intercept & 0.672 & $0.695^{* * *}(0.00029)$ \\
\hline \multirow[t]{2}{*}{ a- } & "Specialization: Company 1 & 0.159 & $0.187^{* *}(0.00032)$ \\
\hline & Company 2 & 0.102 & $0.135^{* *}(0.00024)$ \\
\hline \multirow[t]{3}{*}{ b- } & $\begin{array}{l}\text { Team interdependence } \\
\text { Company } 1\end{array}$ & 2.053 & $0.387^{*}(0.00038)$ \\
\hline & Company 2 & 0.348 & $0.214^{* * *}(0.00054)$ \\
\hline & $\overline{\mathbf{R}^{2}}$ & 0.924 & \\
\hline 2. & Motivation: intercept & 0.378 & $0.692^{\text {**** }}(0.00023)$ \\
\hline \multirow[t]{3}{*}{ a- } & Willingness to seek & & \\
\hline & Company 1 & 0.481 & $0.238^{* * *}(0.0003)$ \\
\hline & Company 2 & 0.089 & $0.097^{* * *}(0.0005)$ \\
\hline & Willingness to share information & & \\
\hline & Company 1 & 0.0036 & $0.00043^{* *}(0.000)$ \\
\hline & Company 2 & 0.00028 & $0.00007^{* *}(0.000)$ \\
\hline & $\mathbf{R}^{2}$ & 0.871 & \\
\hline
\end{tabular}

$(,+*, * * *)$ indicates to significance level at $(\mathbf{1 0 \% , 5 \% , 1 \% ) . ~ L e v e l ~ s t a n d a r d ~ e r r o r ~ a r e ~ i n ~ p a r e n t h e s e s . ~}$

The two estimation models are formulated as:

$$
\begin{aligned}
\mathrm{T}_{\mathrm{kn}}= & 0.672+0.159 \mathrm{speci}_{\mathrm{co} 1}+10.102 \mathrm{spci}_{\mathrm{co} 2}+2.053 \text { Team inter }_{\mathrm{co} 1} \\
& +0.34 \text { inter }_{\mathrm{co} 2}+\sum_{\mathrm{t}} \cdots \cdots \cdots
\end{aligned}
$$

Where: $T_{k n}$ estimated is the structure models of the perecetage of task knowledge.

Specialization indicates for actor.

Specialization for company $1>0$, and ratio for company $2_{1}>0 . \sum$ the stochastic error (team interdependence for company 1$)>0$, and (company 2$)>0$.

The second model is: motivation model of the percentage task-knowledge at time.

$$
\begin{aligned}
\mathrm{T}_{\mathrm{kn}}= & 0.378+0.481 \text { willingne } \mathrm{ss}_{\mathrm{co} 1} \text { to seek }_{\text {estim }}+0.089 \mathrm{~W} . \text { Seek }_{\mathrm{co} 2}+\text { W.share } \\
& +0.00028 \mathrm{~W} . \text { share }_{\mathrm{co} 2}+\sum_{\mathrm{t}} .
\end{aligned}
$$

W.Seek: is willingness to seek,

W.Share: is the willingness to share information with others $\sum_{\mathrm{t}}$ is the stochastic errors. We can draw the relationship model of percentage task-knowledge $\left(\mathrm{T}_{\mathrm{kn}}\right)$ as the following diagram:

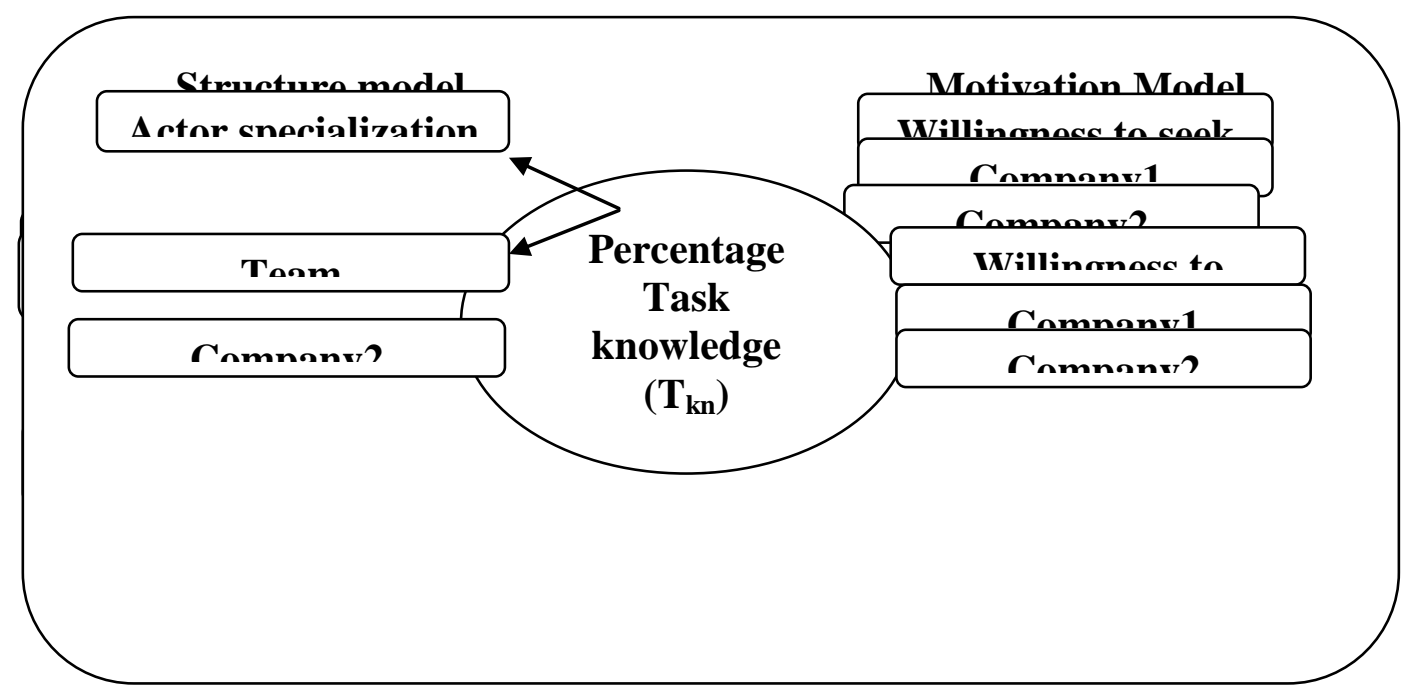


The third hypothesis in this study is the effect of legacy organization culture on post-merger integration.

$$
\begin{aligned}
& \mathrm{T}_{\mathrm{kn}} \text { perecent } 0.754+0.341 \text { org culture comp } \mathrm{co}_{1}-0.635 \text { or culture comp } \mathrm{co}_{2}-0.723 \text { Team cul comp } \mathrm{p}_{\text {comp } 1} \\
&+1.31 \text { Team cul comp } \\
& \text { com2 }
\end{aligned}
$$

All parameters are $>0$ where $\mathrm{T}_{\mathrm{kn}}$ perce is the percentage of organization culture at time, all parameters constrained by $0 \leq \mathrm{T}_{\mathrm{kn}} \leq 1$ and poc constrained by $0 \leq$ poc $\leq 1$.

Poc $=0.865-0.271$ orgcult ure comp-0.371Teamcul comp-0.725Teamcult ure compcom2.

This hypothesis is an investigate into possible interaction between the independent variables in this study, therefore secondary analysis will be done to investigate the multiplicative effect between the structure of culture and the characteristic of culture. Where the independent variables (Controll variables) are contrived for factorialdesinged.

2- test of two sample for means will done to insure of the structural characteristic effect on the post-merger organization table ( ) shows the result of analysis.

Table ( ): Two sample Means -2-test.

\begin{tabular}{|l||l|l||}
\hline & Structure & Cultural \\
\hline \hline Mean & 4.583 & 0.0527 \\
\hline \hline Variance & 51 & 0.0621 \\
\hline \hline Hypothesized Mean deference 2 & 2.338 & \\
\hline \hline $\mathrm{P}(2 \leq 2)$ Entail & 0.094 & \\
\hline \hline Crtical value & 1.0315 & \\
\hline
\end{tabular}

\section{Section five}

\section{Concluded remarks:}

The post-merger acquisition integration study applied to two companies in Jordan which provided clear evidence that structural factors such as work unit task and the number of work team are more relevant to the post-merger integration outcomes than cultural factors. This study used many models, but in general based on an agent-based computational model, specifically construct the behavior of agent depends on the behavioral theory of the firm. Also this study does not account for management's integration strategy that often accompanies a merger. Therefore the study limits the applicability to some operational perspectives. The three hypothesis of this study have been examined through the data set, first hypothesis that post-merger knowledge transfer examining antecedent structural complexity. Where the second hypothesis considered the post-merger integration effect of task structure and motivation to exchange on organization performances and the third hypothesis is "the effects of legacy organization culture on the post-merger integration. The results of analysis indicates that the size of the organization is high and it has a negative effects performance, where the size of team work has a positive affects the performance, and the infrastructure support has a positive affects task performance to a large extent these results are the same result of (Backer \& Wa, 2007). The other finding in the analysis such as, there is less knowledge that must pass between group and also individuals enhance there are more individuals in close proximity that have information the individual tendency to seek out information is positively correlated with performance, and the complexity of culture in both organization and team level hinders task performance finally the willingness to share information or not has virtually no relationship with the performance of the group. The further future works can studied and address the external validity of the results by field-test the quantitative model and compare the results and also the researcher will need to come over the problem of the structural changes on uses of organizational merger and to formulating studies to prove whether the structure are more important them motivation or disprove the over aching concept 


\section{References}

Vaara, E. (2003). Post-acquisition Integration as Sense making: Glimpses of Ambiguity, Confusion, Hypocrisy, and Politicization. Journal of Management Studies, 40(4), 859-894.

Sorenson, R. L. (2000). The Contribution of Leadership Style and Practices to Family and Business Success. Family Business Review, 13(3), 183-200.

Steen, A., \& Welch, L. S. (2006). Dancing With Giants: Acquisition and Survival of the Family Firm. Family Business Review, 19(4), 289-300.

Astrachan, J. H. (2010). Strategy in family business: Toward a multidimensional research agenda. Journal of Family Business Strategy, 1(1), 6-14.

Astrachan, J. H. (1988). Family firm and community culture. Family Business Review, 1(2), 165-189.

Becker, M. C., \& Knudsen, M. P. (2006). Intra and inter-organizational knowledge transfer processes: Identifying the missing links. Danish Research Unit of Industrial Dynamics, DRUID Working Paper No. 06-32.

Becker, B. J., \& Wu, M-J. (2007). The synthesis of regression slopes in meta-analysis. Statistical Science, 22(3), 414429.

Bock, G-W., Zmud, R. W., Kim, Y-G., \& Lee, J-N. (2005). Behavioral intention formation in knowledge sharing: Examining the roles of extrinsic motivators, social-psychological forces, and organizational climate. MIS Quarterly, 29, 87-111.

Bruner, R. F. (2004). Applied mergers \& acquisitions. Hoboken, NJ: Wiley.

Bruner, R. F. (2005). Profiles of the outlying M\&A transactions, 1985 to 2000. http://dx.doi. org/10.21 39/ssrn. 681282.

Carley, K. M. (2003). Dynamic network analysis. In Ronald Breiger, Kathleen M. Carley, and Philippa Pattison (Eds.), Dynamic social network modeling and analysis: Workshop summary and papers (pp. 133-145). Washington, DC: National Research Council.

Carley, K. M., Diesner, J., Reminga, J., \& Tsvetovat, M. (2007). Toward an interoperable dynamic network analysis toolkit. Decision Support Systems, 43, 1324-1347.

Carley, K. M. \& Frantz, T. L. (2009). Modeling organizational and individual decision making. In A. P. Sage \& W. B. Rouse (Eds.), Handbook of systems engineering and management (pp. 723-762). New York: Wiley.

Carley, K. M., Martin, M. M., \& Hirshman, B. (2009). The etiology of social change. Topics in Cognitive Science, 1(4), 621-650.

Carley, K. M. (1986). Knowledge acquisition as a social phenomenon. Instructional Science,14, 381-438.

Elliott, E. \& Kiel, L. D. (2004). Agent-based modeling in the social and behavioral sciences. Nonlinear Dynamics, Psychology, and Life Sciences, 8, 121-130.

Lin, H-F. (2006). Impact of organizational support on organizational intention to facilitate knowledge sharing. Knowledge Management Research \& Practice, 4, 26-35.

Lin, H-F. (2007). Effects of extrinsic and intrinsic motivation on employee knowledge sharing intentions. Journal of Information Science, 33(2), 135-149.

Lin, Z., \& Carley, K. (2003). Designing stress resistant organizations: Computational theorizing and crisis applications. Boston, MA: Kluwer Academic Publishers.

Minbaeva, D. (2005). HRM practices and MNC knowledge transfer. Personnel Review, 34, 125-144.

Morrison, E. W. (2002). Information seeking within organizations. Human Communication Research, 28(2), 229-242.

Robinson, S. (1997). Simulation model verification and validation: Increasing the users' confidence. In S. Andradcttir, K. J. Healy, D. H. Withers, and B. L. Nelson (Eds.),

Proceeding of the 1997 Winter Simulation Conference, The Society for Computer

Simulation, San Diego, CA, (pp. 53-59).

Nemanich, L., \& Vera, D. (2009). Transformational leadership and ambidexterity in the context of an acquisition. The Leadership Quarterly, 20, 19-33.

Pitkethly, R., Faulkner, D., \& Child, J. (2003). Integrating Acquisitions. Advances in Mergers and Acquisitions, 2, 2757.

Schweizer, L., \& Patzelt, H. (2012). Employee commitment in the post-acquisition integration process: The eff ect of integration speed and leadership. Scandinavian Journal of Management, 28(4), 298-310.

Epstein, M. (2004). The Drivers of Success in Post-Merger Integration, Organizational Dynamics, 33(2), 174-189.

Agrawal, S., Dasgupta, A., \& Bansal S. (2011). Pu* ing the pieces together - Post merger integration survey 2010, PwC India. Retrieved March 08, 2011, from h* p://www.pwc.com/in/en/ publications/publications-2011/pu* ing-the-pieces-together. 